\title{
Analysis and Assessment of Graduate Students' Perception and Academic Performance Using Open Educational Resource (OER) Course Materials
}

\author{
Thahomina Jahan Nipa \\ Dr. Sharareh Kermanshachi, University of Texas at Arlington
}

Dr. Sharareh (Sherri) Kermanshachi is an Assistant Professor in the Department of Civil Engineering at the University of Texas at Arlington. Dr. Kermanshachi has received her Ph.D. degree in Civil Engineering from Texas A\&M University. She also holds a Master's degree in Civil Engineering from Mississippi State University and an MBA from Eastern Mediterranean University in Famagusta, Cyprus. Her areas of expertise are performance-based modeling, project delivery methods, communication networks, and uncertainty and risk analysis in design and construction of transportation projects. She also has industrial experience as a project manager in multiple building construction projects. Dr. Kermanshachi has conducted several research projects which were awarded by Texas Department of Transportation (TxDOT), National Cooperative Highway Research Program (NCHRP) and Construction Industry Institute (CII). Dr. Kermanshachi has received several prestigious national and regional awards, including the American Society of Civil Engineers (ASCE) Professional Service Award, ASCE Excellence in Education (ExCEEd) Fellowship, Aggies Commit to Professional Student Educational Experiences, Graduate Teaching Lecturer Fellowship, and Climate Award. She was also the only academic recipient of the Texas and Louisiana Engineering News Record (ENR) Top Young Professional Award in 2017. Dr. Kermanshachi is currently directing a very vibrant construction engineering and education research group and advising several Ph.D. and Master's students 


\section{Analysis and Assessment of Graduate Students' Perception and Academic Performance Using Open Educational Resource (OER) Course Materials}

Ms. Thahomina Jahan Nipa, University of Texas at Arlington

Ph.D. Student, Department of Civil Engineering, University of Texas at Arlington, 425

Nedderman Hall, 416 Yates Street, Arlington, TX 76019. E-mail:

thahomina.nipa@mavs.uta.edu

Dr. Sharareh Kermanshachi, University of Texas at Arlington

(Corresponding Author) Assistant Professor, Department of Civil Engineering, University of Texas at Arlington, 438 Nedderman Hall, 416 Yates Street, Box 19308, Arlington, TX 76019, USA. E-mail: sharareh.kermanshachi@uta.edu 


\title{
Analysis and Assessment of Graduate Students' Perception and Academic Performance Using Open Educational Resource (OER) Course Materials
}

\begin{abstract}
When a professor instructs students to follow a hard book, many financially disadvantaged students are unable to do so. Moreover, in this era of digitalization, students are accustomed to carrying all of the information they need in electronic devices stowed in their pockets, making learning from a book less appealing. Eventually, some of the students either partially or fully sacrifice their educational goals, resulting in a seemingly systematic educational system becoming an ineffective one. Therefore, the aim of this paper is to analyze one of the solutions to this problem, which is the development of a web-based open educational resources (OER) course to replace the traditional textbook-based instructional approach. A graduate-level risk management course was selected as a pilot class for this approach. The web-based system was created and implemented through four sequential phases, with each phase containing several subphases/steps. The first step towards building this web-based course was to select the appropriate educational accessories. It was concluded that image and video types of OER would be most effective for this unique type of course. Hence, a risk management course database was created, using images and current case studies related to construction management risks. Using this database, the virtual system containing OER materials was created, and throughout the semester, the instructor and the graduate teaching assistant monitored students' involvement in the new system. At the end of the semester, a survey was conducted to collect data regarding students' perception of the developed materials and the effectiveness of the OER. The assignment, exam grades, and course project grades were also compared. The data collected from the survey and the numerical grades of the students were assessed both qualitatively and quantitatively. It was concluded that students majoring in engineering and students with loans had a more positive perception of the OER course materials. It was also observed that the students using OER materials received higher grades than the students from the previous semester who had the same instructor but utilized traditional textbook-based materials. The outcome of this study will help OER funding agencies effectively allocate their financial support among potential courses and assist instructors in appropriately designing their course materials based on the financial situation of their students.
\end{abstract}

\section{Introduction}

Education is a very important component of every society ${ }^{1}$, and numerous researchers have conducted studies focusing on effective teaching and learning techniques and strategies. ${ }^{2}$ Many of the studies were conducted to evaluate and analyze the effectiveness of innovative teaching methods ${ }^{3}$ leading some of the researchers to conclude that an educational method or teaching style that is suitable for one group of individuals may not be effective for another group. ${ }^{4}$

The utilization of textbooks is an educational component that has been debated for a very long time. A textbook is a study material which should be easily available and organized for a specific course in a language suitable for the course takers, ${ }^{5}$ and it is traditionally considered the most effective aid in any educational system. This notion tempts a student to think that the textbook 
has every little detail that he or she needs to know about the course; however, that is almost never true, as a textbook is never completely current. In addition, with the growing population of pupils and their dependency on a textbook for education, the demand for textbooks is increasing, and the increasing demand is resulting in higher prices for certain textbooks, making them unavailable to students who are either unable or unwilling to bear the extra cost. In the United States, the prices of textbook rose around $82 \%$ from 2003 to $2013^{6}$. Moreover, technology is advancing rapidly, with new innovations daily, and people are becoming more and more dependent on technology for almost everything. A survey found out that almost $56 \%$ of Americans own a smartphone, and most of them are young adults. ${ }^{7}$ These little gadgets provide a young person with the sense that they have almost everything they need in their pocket and discourages them from carrying one or several textbooks all day for their classes. In fact, a survey conducted of several classes showed that more than $66 \%$ of the students look on the internet for course material before looking into the textbook, regardless of whether the textbook is optional or mandatory for the course. ${ }^{8}$ This is indicative of young students' reluctance to peruse pages of printed textbooks. The aforementioned problems can be resolved by introducing an effective system containing OER.

OER can be defined as a type of course material that enables instructors and students to have access to every educational resource, including course materials, videos, and/or multimedia applications without paying any kind of fee or royalties. ${ }^{9}$ Developing an interactive web-based OER educational system has the potential to enhance the students' performance and eliminate the burden of increased prices. Web-based OER is very appropriate for young adults who are fond of technological devices; hence it should encourage their academic endeavors and enhance their performance. This paper tries to quantify this phenomenon by assessing the effectiveness of OER materials through the interactive online educational system. The perceptions of engineering and non-engineering students, as well as the perceptions of the students with loans and without loan are evaluated. This paper also studies the general effect of OER on students' performance by analyzing their assignment, exam, and project grades.

\section{Literature Review}

Education is a system by which a generation becomes able to take over the tasks of the previous generation and contribute to progress of human civilization. Compromising an effective system of education results in compromising the ability of students to play an efficient role in this process. It is a fact that the prices of hard copies of books are rising. In 2013, a study by the Government Accountability Office $(\mathrm{GAO})^{6}$ showed that the rate at which the price of the textbook is increasing is double the rate of inflation. ${ }^{10}$ On average, a college student spends around $\$ 900$ per year for textbooks, but the State Council of Higher Education for Virginia found that approximately $60 \%$ of students nationwide aren't buying books. The GAO blames the accessories that accompany the books, such as CD ROMs, websites, etc. for the increasing price of textbooks. According to Koch ${ }^{11}$, the high price of textbooks, along with the increase of tuition and fees, makes higher education less accessible to young people. The rising cost of textbooks also increases the need for more financial aid from the federal government, colleges, and universities for an increasing number of eligible students. Textbook markets are a free market without any regulation by a governmental policy, which makes it hard for policymakers to control their cost. Textbook markets also differ from other markets in that the person, i.e. the 
faculty who determines which book to use for a course, doesn't really know the price that the customer, i.e. the students, are going to pay for the book. As a result, they don't give enough consideration to price or affordability when recommending the book. Koch also recommended that publishing new editions of textbooks less often, selling learning packages and textbooks separately, and easing reselling and re-importation of textbook policies might help lower the intensity of this problem.

One of the most effective solutions to this problem can be OER. In the early 1980s, the Massachusetts Institute of Technology initiated the primary concepts of OER, even though it wasn't called that until around 2002. ${ }^{13}$. The concept has become more fully developed with the constant advances in software technology. ${ }^{12}$ Downes ${ }^{14}$ defined OER in two ways: as resources that include software, simulations, course monitoring etc.; and as resource media that includes information and communication technology (ICT). He also mentioned that these resources can be called "open" only when they are free. OER is not only good for readers, as they get access to a greater range of literature, but it is also beneficial for publishers, as it enables them to publish a greater variety of articles. Some researchers are concerned about the sustainability of the OER system, as it does not provide any quick monetary benefit since the users get free access to the material. To solve this problem, endowment models, membership models, donations models, conversion models, contributor-pay models, sponsorship models, institutional models, government models, etc. have been established. According to Johnstone ${ }^{15}$, OER not only helps students, but it also helps instructors to develop their teaching methods by enabling them to monitor their own materials or by comparing their method with another instructor's method. It also helps instructors from developing countries enrich their teaching materials by using OER from esteemed universities.

OER is defined in a myriad of ways by researchers. D'Antoni ${ }^{16}$ agreed with the definition provided in 2002 by the United Nations' Educational, Scientific and Cultural Organization (UNESCO) ${ }^{17}$ which defined OER as a non-commercial process which makes educational resources open to the users with the help of information and communication technologies. She explained the roles of the four main stakeholders of the OER system: higher education institutions with the responsibilities of research, raising awareness, and capacity development; international bodies with the responsibilities of copyrights, financing, and standards; national governments with the responsibilities of policy support and accessibility; and academics. Another researcher named Hylen ${ }^{13}$ agrees with the definition of OER as digitized educational materials that are, with as few legal and monetary restrictions as possible, available for use by educators, students, and self-learners and that can be reused and adapted as needed by the users. Several open and public licensing systems by non-profit organizations exist, such as creative commons and free and open-source software (FOSS), which permits students to use and repurpose the materials more easily than a copyright. ${ }^{18}$ However, freeing students of the burden of buying textbooks or making the materials free and accessible to all is a controversial matter, as evidenced by a company who was sued by three major academic publishers in April 2012 for offering free textbooks to any institution. ${ }^{8}$

Some students show preference towards global learning styles, and some prefer sequential learning styles; course materials should be recommended based on their preference. ${ }^{14}$ The traditional textbook system is unable to recognize the difference, but the newly developed 
interactive web-based system recognizes this problem based on the student's participation and feedback on the website. Instructors and graduate teaching assistants can help students in this regard, based on their feedback, making the materials more suitable for the students. As a result, most of the students benefit from development of an OER system.

\section{Research Methodology and Data Collection}

A four-step research approach was adopted for this study, as shown in Figure 1. The first step was the review of the literature for the students' perception and understanding of the existing educational systems and resources. It was helpful to identify the problems of the traditional textbook-dependent educational system, as well as to consider the students' outlooks towards this system and their inclination towards technology. To compare the effect of OER on different types of students, a graduate level course was offered by the Department of Civil Engineering (CE) at the University of Texas at Arlington to both engineering and non-engineering students. The enrollees were students from both construction management and construction engineering programs.

The second step was the development of the new web-based OER system, which can be divided into three phases, including several sub-phases, as shown in Figure 1. The first phase was the pre-system development process. Prior to the beginning of the semester, a comprehensive literature review was done to understand what kind of OER best suits the students. It was found that images and videos are the most effective types of OER, and video tutorials and homework exercises are the second and third most popular item of OER, respectively. Based on this information, the OER materials suitable for the students were gathered and designed. In the second phase, the system development process phase, a website was developed, with related OER materials pertaining to risk management, and full access was given to the students. In the third phase, the post-system development process phase, the students' involvement in the newly developed website was monitored regularly. During the class, they were encouraged to engage themselves in the development of OER materials.

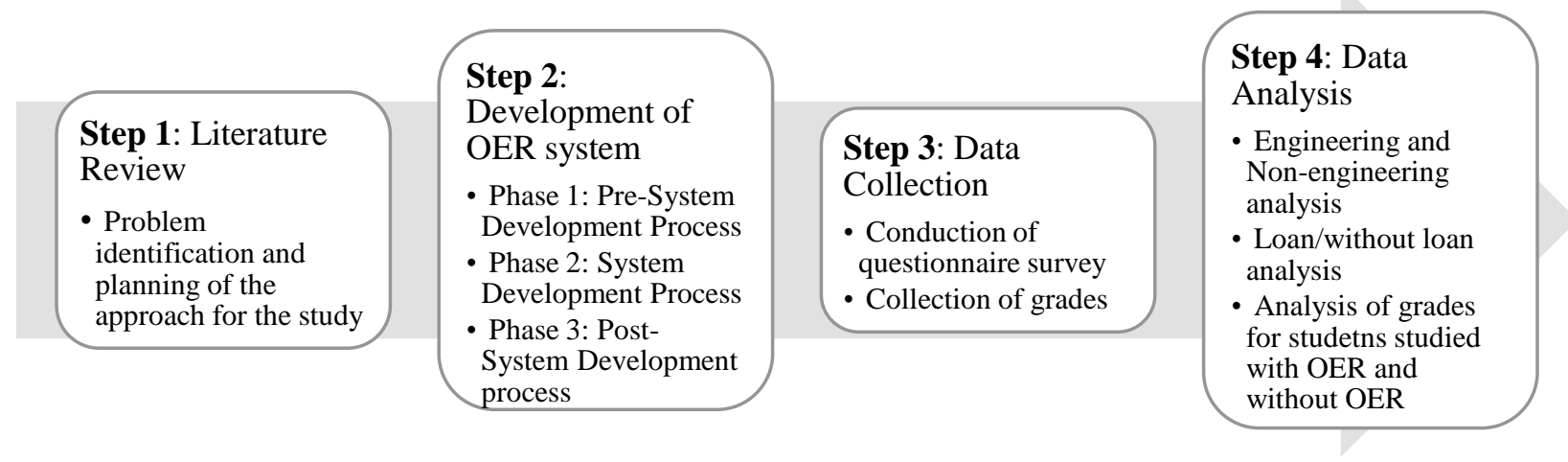

Fig. 1. Research Methodology Process

The third step was the data collection part of the study. One set of data was collected from a questionnaire survey conducted at the end of the semester to anonymously record the students' responses toward the new system. The whole process was conducted for the risk management class that was taught by the same instructor who taught the class the previous semester, using 
traditional textbook materials, the full class participated in the survey. Twelve (12) engineering students and 37 management students voluntarily participated in this survey. However, the number of responses for each variable differed slightly, as some of the questions of the survey were left blank by some of the participants. The survey mostly followed a Likert system of questions and included 19 variables. The students were assessed based on their degree program and financial status. To understand the effect of OER on the general performance of the students, the grades achieved by students following the traditional textbook system the previous semester and the grades achieved by students following the OER system were recorded separately.

In the fourth step, the collected data was analyzed. A statistical test method, two-sample t-test, was selected for analyzing the data and is described later in this paper. This test was selected because it is best suited to establishing the purpose of the study, which was to get a clear understanding of the perceptions of the web-based interactive OER materials of students of different academic and financial backgrounds. In addition, statistical charts were developed to understand the nature of the data, and multiple comparative analyses were done, comparing groups of students and considering different variables.

Hypothesis for the First Set of Analysis:

Engineering and non-engineering students

Null Hypothesis: $\mathrm{H}_{\mathrm{o}}$ : There is no significant difference between the perceptions of engineering and non-engineering students towards OER materials.

Alternate hypothesis, $\mathrm{H}_{\mathrm{a}}$ : There is a significant difference between the perceptions of engineering students and non-engineering students towards OER materials.

\section{Hypothesis for the Second Set of Analysis:}

Students with loans and without loans

Null hypothesis, $\mathrm{H}_{\mathrm{o}}$ : There is no significant difference between the perceptions of students with loans and students without loans towards OER materials.

Alternate hypothesis, $\mathrm{H}_{\mathrm{a}}$ : There is a significant difference between perception of students with loans and students without loans.

Hypothesis for the grades:

Null hypothesis, $\mathrm{H}_{\mathrm{o}}$ : There is no significant difference between the grades of students who use OER course materials and students who use traditional course materials.

Alternate hypothesis, $\mathrm{H}_{\mathrm{a}}$ : There is a significant difference between the grades of students who use OER course materials and students who use traditional course materials.

\section{Data Analysis}

The two-sample t-test utilized in this study is a hypothesis testing system which compares the means of two groups to determine whether there is a significant difference between them or whether the difference is generated randomly. For this study, the two-sample t-test was performed for both of the pairs. For each pair, two hypotheses were developed, as explained earlier. Data from each group was compared with the data from the other set through utilization of the two-sample t-test, and the corresponding p-values were calculated. P-values were then compared with a predetermined level of significance. ${ }^{19}$ For this study, the author chose $10 \%$ as 
the level of significance. This illustrates that a p-value greater than 0.1 agrees with the null hypothesis, and a p-value smaller than 0.1 rejects the null hypothesis by supporting an alternate hypothesis. The authors used SPSS statistics software for their calculations of the t-tests. A sample outcome of SPSS statistics software is shown in Figure 2 for the variable 9 (comfort while using material) for engineering and non-engineering students.

\begin{tabular}{|c|c|c|c|c|}
\hline \multicolumn{5}{|c|}{ Hypothesis Test Summary } \\
\hline & Null Hypothesis & Test & Sig. & Decision \\
\hline 1 & $\begin{array}{l}\text { The distribution of } \\
\text { NonEngineeringStudentsvs } \\
\text { EngineeringStudentvg is the same } \\
\text { across categories of } \checkmark 2 \text {. }\end{array}$ & $\begin{array}{l}\text { Independent- } \\
\text { Samples } \\
\text { éruskal- } \\
\text { vilallis Test }\end{array}$ & .091 & $\begin{array}{l}\text { Reject the } \\
\text { null } \\
\text { hypothesis. }\end{array}$ \\
\hline
\end{tabular}

Asymptotic significances are displayed. The significance level is 10 .

Fig. 2. Sample Result of SPSS statistics software for V9 of engineering and non-engineering students.

\section{Results}

\section{Survey-Based Analysis of Students' Perception of OER:}

The web-based OER system can help students by providing plenty of useful features. Keeping that in mind, 19 variables were selected, and Figure 3 makes it clear that these features were well liked by the majority of the students. For example, around $90 \%$ of the students thought that this system provides better quality visuals and helps them review and remember material more easily than the traditional textbook system. Most importantly, around $90 \%$ of the students believed that the outcomes of the web-based OER materials exceeded those of the traditional textbook approach. Further discussion on determining the suitability of OER for the groups is presented in the following paragraphs.

\section{Pair 1. Engineering and non-engineering students}

As shown in Table 1, irrespective of their major, students found OER helpful, as it enables them to access course material whenever they need it ( $p$-value- 0.101 ) and provides better search capabilities (p-value- 0.151) for a particular topic than the traditional textbook system. This quality of OER encourages them to take useful notes on the materials ( $p$-value- 0.531 ). Thus, OER shut out other distractions while studying (p-value- 0.295 ) and made the students more attentive. However, different options of educational approaches prepare students to process information differently. For example, engineering students are more research oriented and are commonly interested in the basic principles of engineering, whereas management students are more interested in the practical application of the knowledge they acquire. For this reason, the former group of students is more likely to be interested in the high-quality visuals (p-value- 0.05) and useful and helpful aids (p-value- 0.062) offered by OER, which helps them find more relative (p-value- 0.042) and current content (p-value- 0.083) than the traditional textbook system. As it is an interactive system, OER students can collaborate with fellow students ( $\mathrm{p}$ value- 0.042), and they can prepare for class activities or discussions (p-value- 0.091) by reviewing the material ( $\mathrm{p}$-value- 0.041 ), which could not be facilitated through adoption of the traditional textbook approach. 


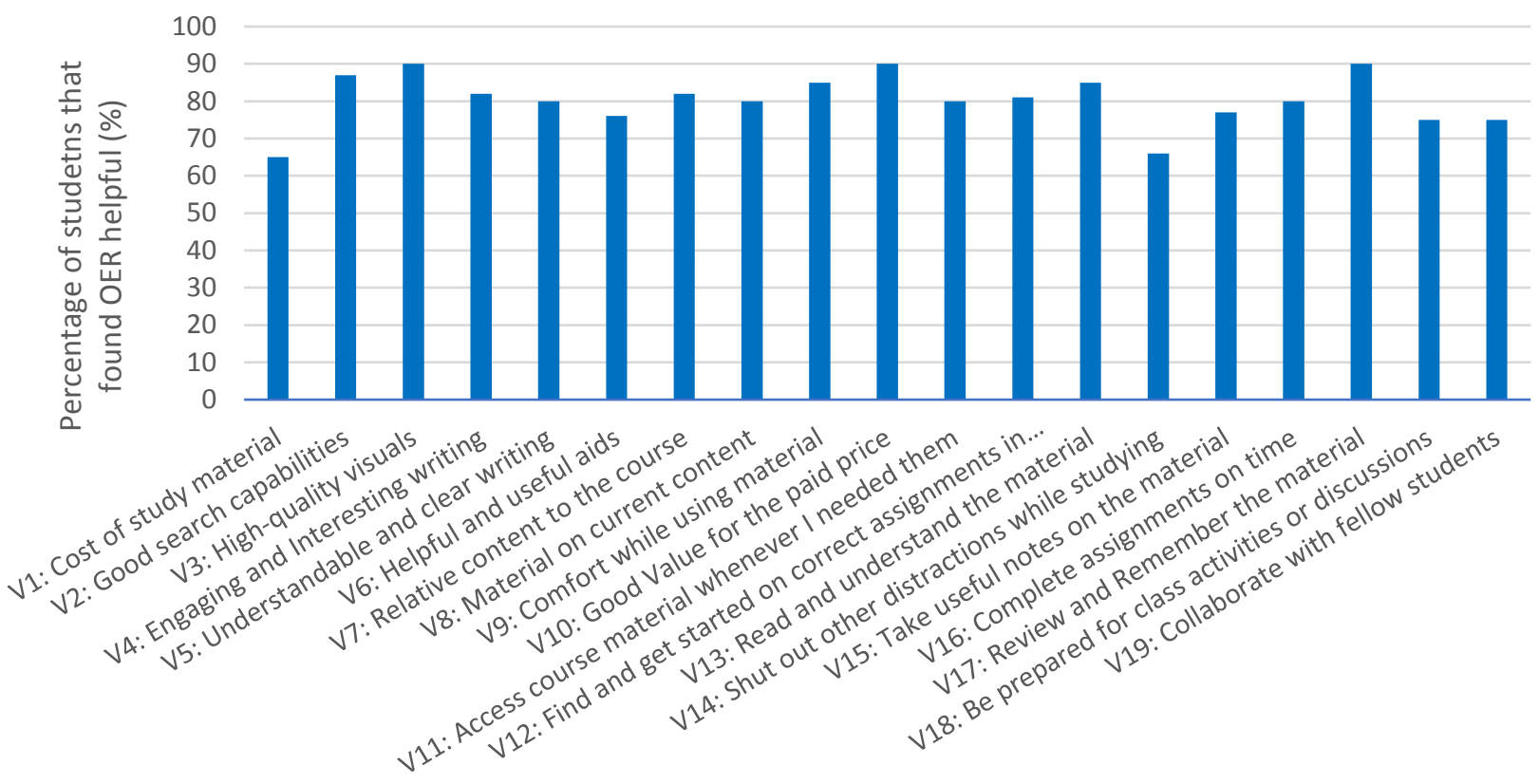

Fig. 3. Graphical Representation of percentage of the students' preference towards OER materials for different variables.

Students using OER materials do not have to carry heavy books, which makes studying in libraries or other educational places more comfortable (p-value- 0.091). Also, OER helps students start their assignments on time (p-value- 0.066) resulting in completing their assignments on time (p-value- 0.066).

\section{Pair 2. Students with loans and without loans}

As illustrated in Table 1, although irrespective of their way of managing tuition, most of the students found that OER prepares them for class activities or discussions ( $\mathrm{p}$-value - 0.192) more effectively than the traditional textbook system by providing high quality materials (p-value0.242 ), exposing them to engaging and interesting writing (p-value- 0.258), and shutting out other distractions (p-value- 0.228). Some of the students found some qualities of the OER system more helpful than others. Students with loans have more financial constraints and might not have the ability to purchase a course book. In fact, the very first variable agrees with this assumption, as it shows that students with loans are less willing to bear the cost of study materials (p-value0.08 ) compared to students without loans. This unwillingness encourages them to utilize the OER system to its fullest, resulting in their having better search capabilities (p-value- 0.087), more relative (p-value- 0.074) and current content (p-value- 0.076), more helpful and useful aids (p-value- 0.074), and greater access to materials whenever they are needed (p-value- 0.067) compared to the students without loans. They also feel more comfortable while using (p-value0.054) OER materials than students without loans. The box plots of Figure 4 and the p-value $(0.068)$ for the variable "take useful notes on the material" show that students with loans are better at taking notes when they use OER materials compared to the students without loans. This behavior helps them to read and understand the material (p-value- 0.09), find and get started on correct assignments, (p-value- 0.09), and complete assignments on time (p-value- 0.083). 
Table 1. P-values testing the significance of students' perception difference adopting OER based on major and loan status

\begin{tabular}{|c|c|c|c|}
\hline Serial & Variables & $\begin{array}{c}\mathrm{P} \text { values for } \\
\text { Engineering and } \\
\text { non-engineering } \\
\text { students }\end{array}$ & $\begin{array}{c}\text { P values for } \\
\text { students with } \\
\text { loan and students } \\
\text { without loan }\end{array}$ \\
\hline $\mathrm{V} 1$ & Cost of study material & $0.064^{*}$ & $0.08^{*}$ \\
\hline $\mathrm{V} 2$ & Good search capabilities & 0.151 & $0.087 *$ \\
\hline V3 & High-quality visuals & $0.05^{*}$ & 0.242 \\
\hline V4 & Engaging and interesting writing & $0.03 *$ & 0.258 \\
\hline V5 & Understandable and clear writing & $0.06^{*}$ & $0.093 *$ \\
\hline V6 & Helpful and useful aids & $0.062 *$ & $0.074 *$ \\
\hline V7 & Relative content to the course & $0.042 *$ & $0.074 *$ \\
\hline V8 & Material on current content & $0.083^{*}$ & $0.076^{*}$ \\
\hline V9 & Comfort while using materials & $0.091 *$ & $0.054 *$ \\
\hline V10 & Good Value for the paid price & 0.114 & $0.038 *$ \\
\hline V11 & Access course material whenever needed & 0.101 & $0.067 *$ \\
\hline V12 & Get started on correct assignments in time & $0.066^{*}$ & $0.09 *$ \\
\hline V13 & Read and understand the material & $0.072 *$ & $0.073 *$ \\
\hline V14 & Shut out other distractions while studying & 0.295 & 0.228 \\
\hline V15 & Take useful notes on the material & 0.531 & $0.068^{*}$ \\
\hline V16 & Complete assignments on time & $0.066^{*}$ & $0.083 *$ \\
\hline V17 & Review and remember the material & $0.041^{*}$ & $0.09 *$ \\
\hline V18 & Be prepared for class activities or discussions & $0.091 *$ & 0.192 \\
\hline V19 & Collaborate with fellow students & $0.042 *$ & $0.081^{*}$ \\
\hline
\end{tabular}

*indicates significant difference with $90 \%$ level of confidence

As the students using the OER materials have greater access to material as opposed to those using the traditional textbook system, they are more collaborative with fellow students (p-value0.081) than students without loans who are more dependent on the textbook. Hence, more students with loans feel that the outcome this system gives a good value for the price (tuition) they paid (p-value- 0.038) compared to students without loans. Based on this discussion it can be said that offering free materials releases some burdens from students with loans and increases their preparedness for class.

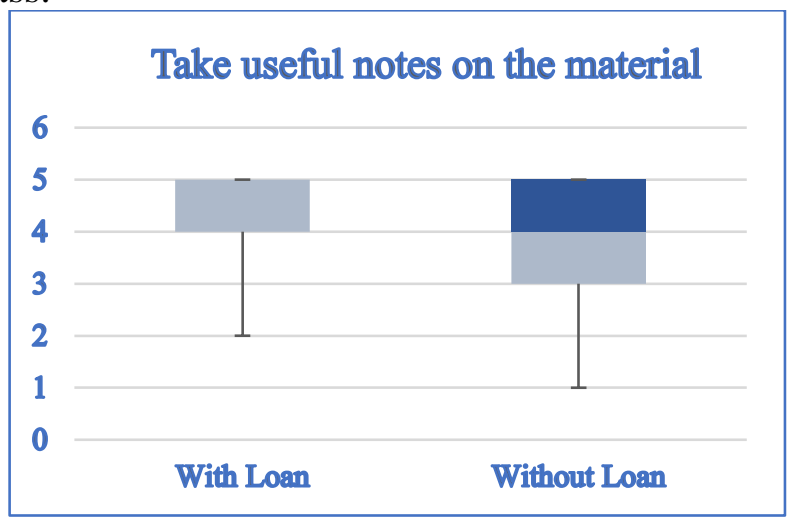

Fig. 4. Box plot for students' perception on taking useful notes based on their loan status 
Based on the earlier discussions and Figure 5(a), it can be said that most of the identified OER variables favor the alternate hypothesis for pair 1 . It is evident that engineering students will benefit more from the web-based OER system than non-engineering students. However, the students' perception for most of the variables is affected by whether or not they have loans for their tuition and fees. From Figure 5(b), it can be seen that with few exceptions, most of the variables support the alternate hypothesis of the second set of analysis. This means that OER material enables students with loans to prepare for the future better than students without loans.
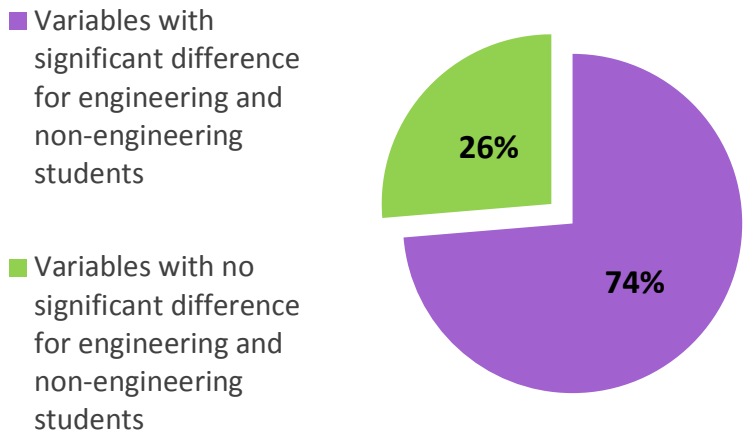

(a)
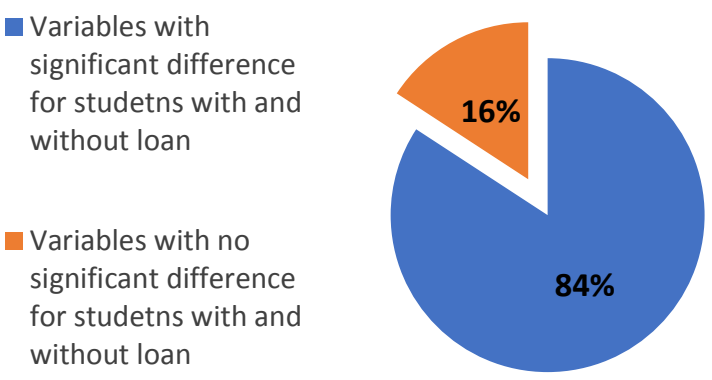

(b)

Fig. 5. Ratio of number of significant variables to non-significant ones (a) for engineering and non-engineering students \& (b) for students with loan and without loan.

\section{Analysis of Students' Grades Using OER Course Materials}

The collected grades for eight assignments, two exams, and three course projects in two consecutive semesters, one using OER materials and one using a traditional textbook as the reference material in the class, were analyzed. The statistical results of the tests, using the twosample t-test, and their p-values are shown in Table 2. From the p-values of Table 2 and box plots of grades shown in Figure 6, it is indicated that the overall performance of the students using OER materials in the risk management course was better than that of the students who did not use the OER material.

Table 2. P-values of grades of students studied with OER and without OER

\begin{tabular}{lr}
\hline Topic & P-values \\
\hline Assignment 1 & $0.093^{*}$ \\
\hline Assignment 2 & $0.069^{*}$ \\
\hline Assignment 3 & $0.008^{*}$ \\
\hline Assignment 4 & $0.000^{*}$ \\
\hline Assignment 5 & $0.000^{*}$ \\
\hline Assignment 6 & $0.003^{*}$ \\
\hline Assignment 7 & $0.007^{*}$ \\
\hline Assignment 8 & $0.000^{*}$ \\
\hline Case Study Analysis & $0.095^{*}$ \\
\hline Individual Final Project & $0.000^{*}$ \\
\hline Mid-Term Exam & $0.000^{*}$ \\
\hline Final Exam & $0.000^{*}$ \\
\hline *indicates significant difference with 90\% level of confidence
\end{tabular}



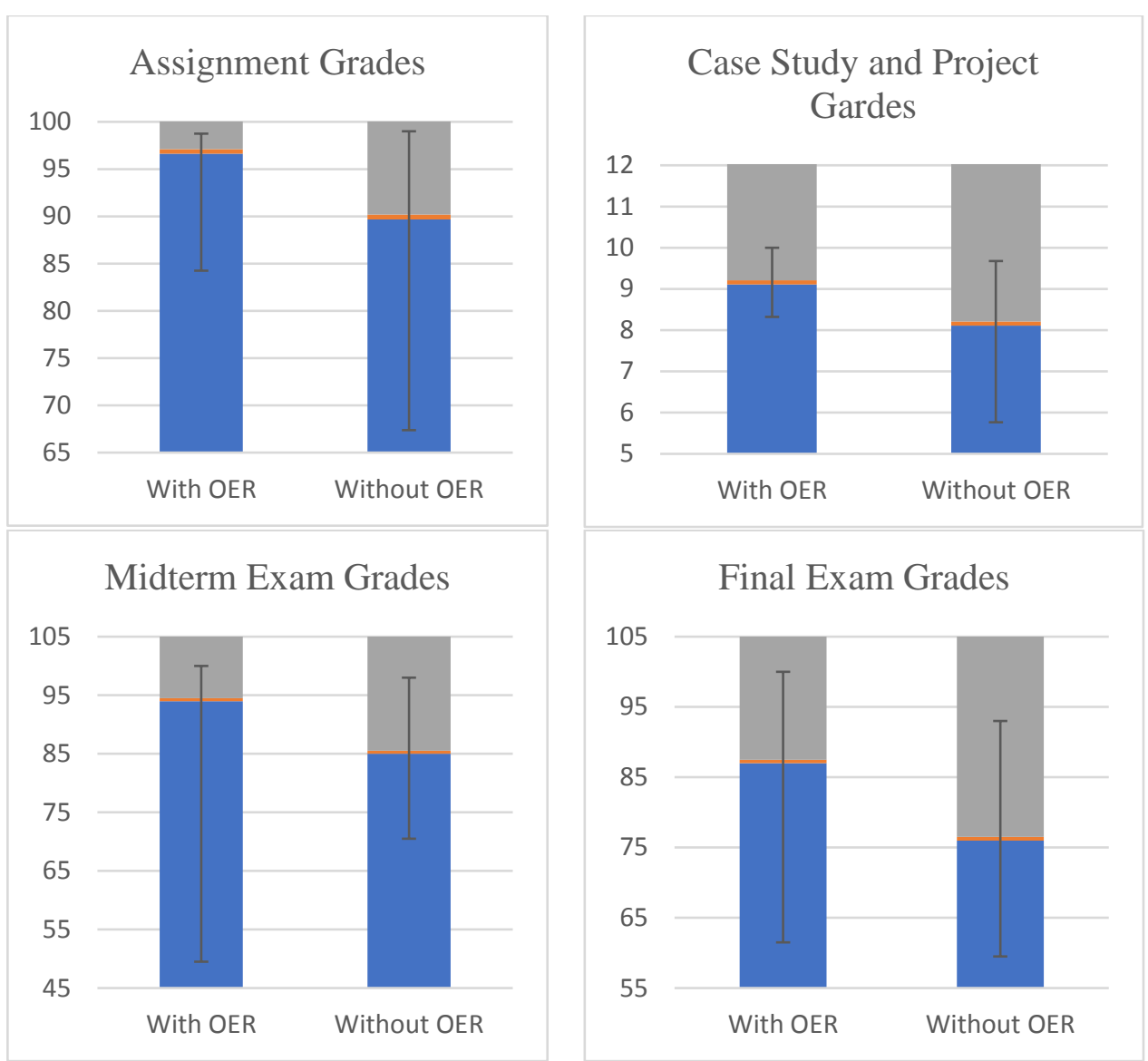

Fig. 6. Box plots for students' grades studied with OER and without OER Course Materials

\section{Conclusion}

This study analyzed and assessed the usefulness of web-based OER materials to eliminate the problem of the ever increasing prices of textbooks. After analyzing the data, using various statistical analysis methods, the results were presented in a self-explanatory way, using charts, diagrams, and tables. Based on the results, three conclusions were reached. First, engineering students enrolled in the risk management course had a more positive perception towards OER materials than non-engineering students. Second, students with loans had a more positive perception regarding the OER materials compared to students without loans. Third, for the graduate level risk management course, the academic performance of the students utilizing OER materials, based on the grades of their assignments, exams, and course projects, was better than that of the students using traditional textbooks. From these three corollaries, the authors concluded that OER materials could be well suited for developing risk management course materials if the course is offered in the engineering department. Moreover, if the majority of the students have financial constraints, it is recommended that the course professor consider utilization of OER materials, as it relieves the stress of purchasing course textbooks. The findings of this study can help funding program managers effectively distribute and award OER grants and invest the resources in areas/majors were the best outcome is expected. 


\section{Acknowledgement}

This research was supported by the University of Texas at Arlington (UTA) CARES Grant Program, which is sponsored by UTA Libraries. The authors also wish to thank Michelle Reed, UTA's Open Education Librarian, for providing the survey used in this study and offering feedback on this paper.

\section{References}

1. Kermanshachi, S. and Safapour, E. (2017), "Assessing Students' Higher Education Performance in Minority and Non-Minority Serving Universities," Proceedings of Frontiers in Education (FIE), IEEE, Indianapolis, Indiana, October 3-6 2017.

2. Taneja, P., Safapour, E. and Kermanshachi, S., (2018), "Assessment of Implementation Trends in Utilizing Innovative Teaching Techniques in Engineering" Proceedings of ASEE Annual Conference and Exposition, Salt Lake City, UT, June 24-27, 2018.

3. Kermanshachi, S., Anderson, S., Molenaar, K., and Schexnayder, C. (2018), "Effectiveness Assessment of Transportation Cost Estimation and Cost Management Workforce Educational Training for Complex Projects", Proceedings of ASCE International Conference on Transportation \& Development, Pittsburgh, PA, July 15-18, 2018.

4. Kermanshachi, S. and Sadatsafavi, H., (2018), "Predictive Modeling of U.S. Transportation Workforce Diversity Trends: A Study of Human Capital Recruitment and Retention in Complex Environments", Proceedings of ASCE International Conference on Transportation \& Development, Pittsburgh, PA, July 15-18, 2018.

5. Sala, J. R., Why Textbooks? Taylor \& Francis, LTD., Improving College and University Teaching, 1963, Volume 11, No. 2 (spring), pp 76-77

6. College Textbooks: Students Have Greater Access to Textbook Information, United States Government Accountability Office, Report to Congressional Committees, 2013, GAO-13-368

7. Smith, A., Smartphone Ownership 2013, Pew Research Center, Internet \& Technology 2013

8. Swanson, R. A., A Relationship Analysis: A Professor, 500 Students and an Assigned Textbook, Society for History Education, A History Teacher, 2014, Volume 47, No. 2, pp. 289302

9. Butcher, N., A Basic Guide to Open Educational Resources (OER). Vancouver \& Paris: COL \& UNESCO, 2011

10. Kinzie, S., Swelling Textbook Costs Have College Students Saying 'Pass', Washington Post Staff Writer, 2006, A01

11. Koch, J. V., An Economic Analysis of Textbook Pricing and Textbook Markets, ACSFA College Textbook Cost Study Plan Proposal, 2006

12. Caswell, T., Henson, S., Jensen, M., and Wiley, D., Open Educational Resources: Enabling Universal Education, International Review of Research in Open and Distance Learning, 2008, Volume 9, Number 1, ISSN 1492-3831

13. Hylen, J., Open Educational Resources: Opportunities and Challenges, OECD-CERI, 2005.

14. Downes, S., Models for Sustainable Open Educational Resources, Interdisciplinary Journal of Knowledge and Learning Objects, National Research Council of Canada, 2007 
15. Johnstone, S. M., Open Educational Resources Serve the World, Educause Quarterly, 2005, Number 3

16. D'Atoni, S., Open Educational Resources: Reviewing Initiatives and Issues, Open Learning: The Journal of Open, Distance, and e-learning, 2009, Volume 24, Number 1, pp 3-10

17. Forum on the impact of open courseware for higher education in developing countries: Final report, UNESCO, 2002

18. Open Educational Resources-Licensing and Types, en.wikipedia.org

19. Hanna, A. S., Camlic, R., Peterson, P. A., and Nordheim, E. V., Quantitative Definition of Projects Impacted by Change Orders, Journal of Construction Engineering and Management, 2002, Volume 128, No. 1(57) 